\title{
Morphological Changes Under the Influence of Surfactants of FeSe Fabricated from Single Source Precursor Via AACVD with Mechanism and Photocatalytic Activity
}

\author{
Raja Azadar Hussain, Amin Badshah*, Malik Dilshad Khan and Farida Ahmad \\ Department of Chemistry, Quaid-i-Azam University, Islamabad, Pakistan
}

*Corresponding author: Amin Badshah, Department of Chemistry, Quaid-i-Azam University, 45320, Islamabad, Pakistan, Email: aminbadshah@yahoo.com

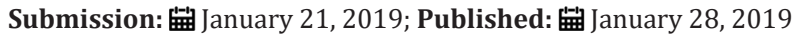

\begin{abstract}
This article presents the conversion of a single source precursor namely 1-(4-methoxybenzoyl)-3-(4-ferrocenylphenyl) selenourea (P4Me) to FeSe by aerosol assisted chemical vapor deposition under the influence of two surfactants i.e. triton X-100 and span. Fabricated films were characterized with PXRD, SEM and EDS. The interaction of surfactants with precursor was investigated with cyclic voltammetry to have the glimpse about the mechanism of morphological changes. Fabricated films have the ability to degrade the methyl violet in the presence of direct sun light.
\end{abstract}

Keywords: Chemical vapor deposition; Dye degradation; Surfactants

\section{Introduction}

For films fabrication of binary inorganic materials, chemical vapor deposition (CVD) is one of the choices but different modifications of CVD are now available depending upon the type of film required and availability of the precursors. The main issue with low pressure CVD [1], atmospheric pressure CVD [2], plasma enhanced CVD [3], laser assisted CVD [3], liquid injection CVD and molecular beam epitaxy [4] is that if the precursor is not volatile then these techniques cannot be used. Aerosol assisted chemical vapor deposition (AACVD) has the advantage of its dependence on solubility rather than volatility which enhances its applications.

Interest in FeSe has been developed mainly after the discovery of superconductivity [5] in it. Photocatalytic activity [6] and electrochemical sensing [6] have also been recently reported in FeSe. Until now FeSe has been fabricated with almost every method available in material science i.e. electrodeposition [7], pulsed laser deposition [8], chemical vapor transport [9], chemical bath deposition [10], chemical vapor deposition [11]. spray pyrolysis [12], molecular beam epitaxial growth [13], solid state reaction [14], solid state reaction at different sintering temperatures [15], thick films from high temperature solution [16], and rapid solventless reaction under autogenic pressure at elevated temperature (RAPET) etc., [17]. Moreover, particle size, orientation, morphology, corrosion properties, mechanical strength, luminescent properties and photoelectric properties of the deposited materials have shown their dependence on the nature and type of surfactant in the liquid phase [18] but the effect of the surfactant in gas phase i.e. AACVD has been rarely reported [19-22].

This article presents the morphological changes of FeSe films fabricated from a single source precursor namely 1-(4-methoxybenzoyl)-3-(4-ferrocenylphenyl) selenourea (P4Me) by AACVD under the influence of surfactants (triton and span). We have also made an effort to determine the mechanism of surfactant action by evaluating the interactions between the surfactants and the precursor with cyclic voltammetry (CV). These films can degrade the methyl violet dye in direct sunlight.

\section{Materials and Methods}

FeSe thin films were characterized with $\mathrm{CuK} \alpha$ radiation of $0.154 \mathrm{~nm}$ between diffraction angles 10-80. SEM images were taken on a SEM JEOL model, $5910 \mathrm{LV}$ with an accelerating voltage of $20 \mathrm{kV}$ at high vacuum (HV) mode and secondary electron image (SEI). The semi quantification elemental analysis to find out the weight percentages of the elements were carried out by using OXFORD INCA energy dispersive X-Ray spectrometer 7274 (EDS).

Cyclic voltammetry was performed on Biologic SP-300 cyclic voltammeter running with EC-Lab Express V 5.40 software, Japan. Before every reading working electrode was polished with alumina powder and rinsed with distilled water. Analytical grade $\mathrm{KCl}$ was used as supporting electrolyte and nitrogen gas (99.9\%) was purged through the mixture to avoid interference of oxygen. CV 
behavior was evaluated with a setup having three electrodes system i.e. working (platinum disc electrode) reference $(\mathrm{Ag} / \mathrm{AgCl})$ and auxiliary electrodes (platinum wire electrode). Values of diffusion coefficients were determined by following form of Randles-Sevcik equation [23]:

$$
\mathrm{I}_{\mathrm{pa}}=2.69 \times 10^{5} n^{\frac{3}{2}} \mathrm{AC}_{o}^{*} \mathrm{D}_{o}^{\frac{1}{2}} v^{\frac{1}{2}}
$$

Where $\mathrm{I}_{\mathrm{pa}}$ is the anodic peak current, $\mathrm{C}_{\mathrm{o}}{ }^{*}$ is the reductant's concentration in molcm$^{-3}, \mathrm{~A}$ is the geometric area of the electrode in $\mathrm{cm}^{2}, \mathrm{n}$ is the number of electrons involved in the process, $\mathrm{D}_{\mathrm{o}}$ is the diffusion coefficient in $\mathrm{cm}^{2} \mathrm{~s}^{-1}[24]$.

\section{Fabrication of FeSe films by AACVD}

$1 \times 1.3 \mathrm{~cm}$ dimension cuttings of the microscope glass slides were used to grow thin films. Before the film deposition, these substrates were placed in a mixture of sulfuric acid and nitric acid for $24 \mathrm{~h}$. After removing from this mixture, they were washed with distilled water two times and sonicated for $30 \mathrm{~min}$. Finally, they were washed with acetone and dried in an oven at $100^{\circ} \mathrm{C}$. FeSe thin films were deposited using AACVD kit equipped with CARBOLITE furnace (21-101847, type MTS10/15/130) and Deurer living LB44 humidifier, having ultrasonic system on glass substrates. Optimized concentrations of P4Me $(0.08 \mathrm{~g})$ were dissolved in $15 \mathrm{~mL}$ of toluene in a two necked round bottom flask $(100 \mathrm{~mL})$ equipped with a glass inlet. This inlet was attached to one of the necks to allow the transport of aerosol under the constant flow of argon $(160 \mathrm{sccm}$ for 1.5 hours) with varying concentrations of the surfactants (triton and span) for all the fabricated thin films (except for the film a in which no surfactant was used). In this setup a tube connects the round bottom flask with the reactor tube which was held at desired temperature. The flow rate of argon is controlled with platon flow gauge and kept constant for all the films. Round bottom flask containing the precursor rests on a water bath above piezoelectric modulator of an ultrasonic humidifier. Humidifier generated the aerosol which was moved to hot zone of the reactor where thermally induced reaction generated the FeSe films.

\section{Dye degradation study}

Film fabricated without using any surfactant was suspended in $10 \mathrm{~mL}$ aqueous solution of methyl violet (MV) having an absorbance value of 1.5 under direct sunlight. The solution containing the film was gently shaken manually after every five minutes. The absorbance of this solution was remeasured after $\sim 25$ minutes to have a glimpse about the degradation. Control was also set in parallel in which only MV solution was placed to have information about its degradation in direct sunlight and it was negligibly degraded.

\section{Synthesis and characterization of the precursor}

We have already published the synthesis and biological applications of P4Me (Scheme 1) [20-29].

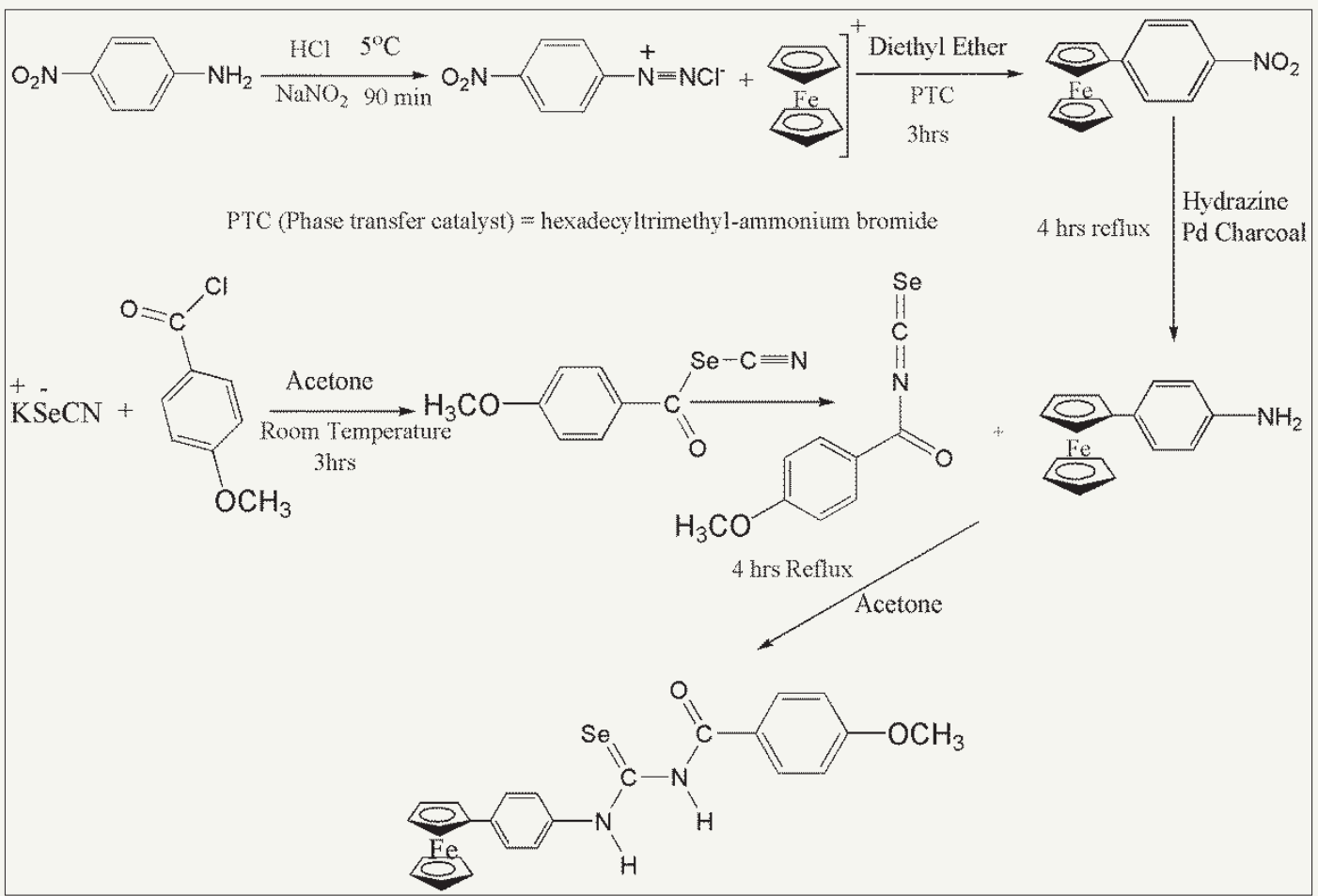

Scheme 1: Synthesis of 1-(4-methoxybenzoyl)-3-(4-ferrocenylphenyl) selenourea(P4Me).

\section{Results and Discussion}

Thermogravimetric analysis of the precursor (P4Me) shows that it completely decomposes to FeSe at $450^{\circ} \mathrm{C}$. So, it was selected as the temperature of furnace during AACVD (Figure 1). PXRD patterns of the seven films (a-g) have been presented in Figure 2 and all the films show predominantly NiAs type hexagonal FeSe lattice i.e. by changing the concentration of the surfactants with the precursors during AACVD, phase of the materials is not effected. 


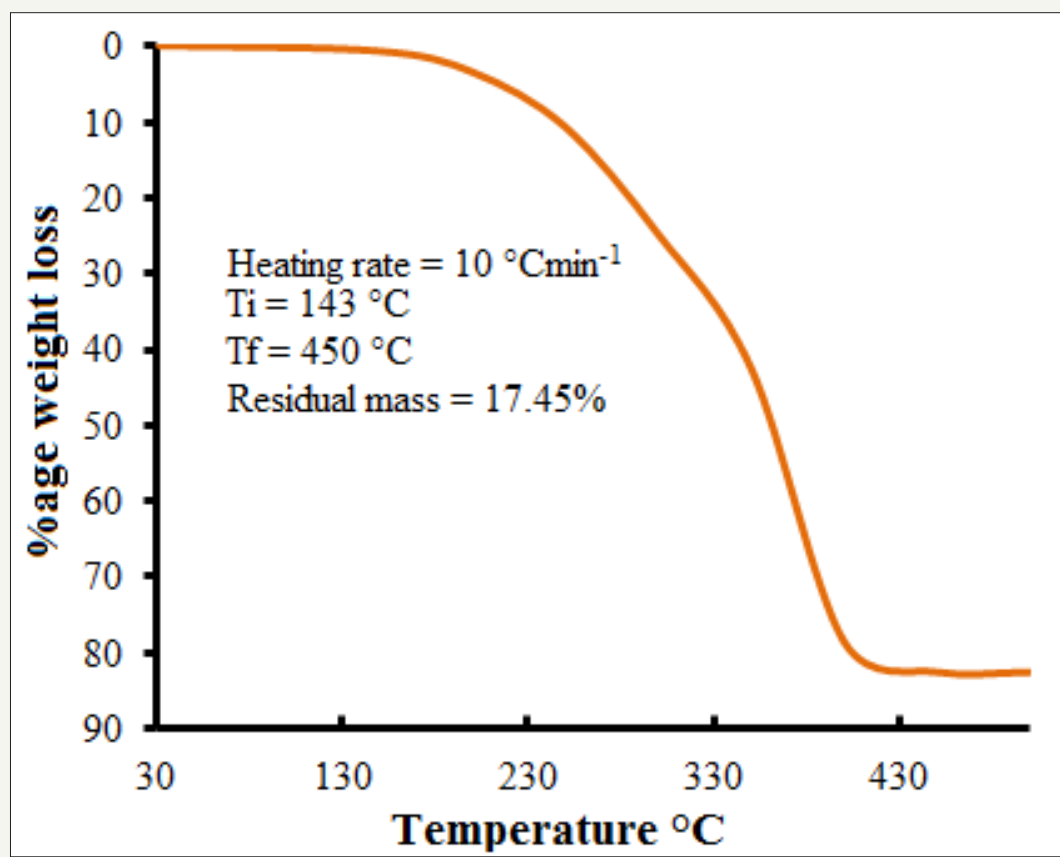

Figure 1: Thermogravimetric analysis of 1-(4-methoxybenzoyl)-3-(4-ferrocenylphenyl) selenourea.

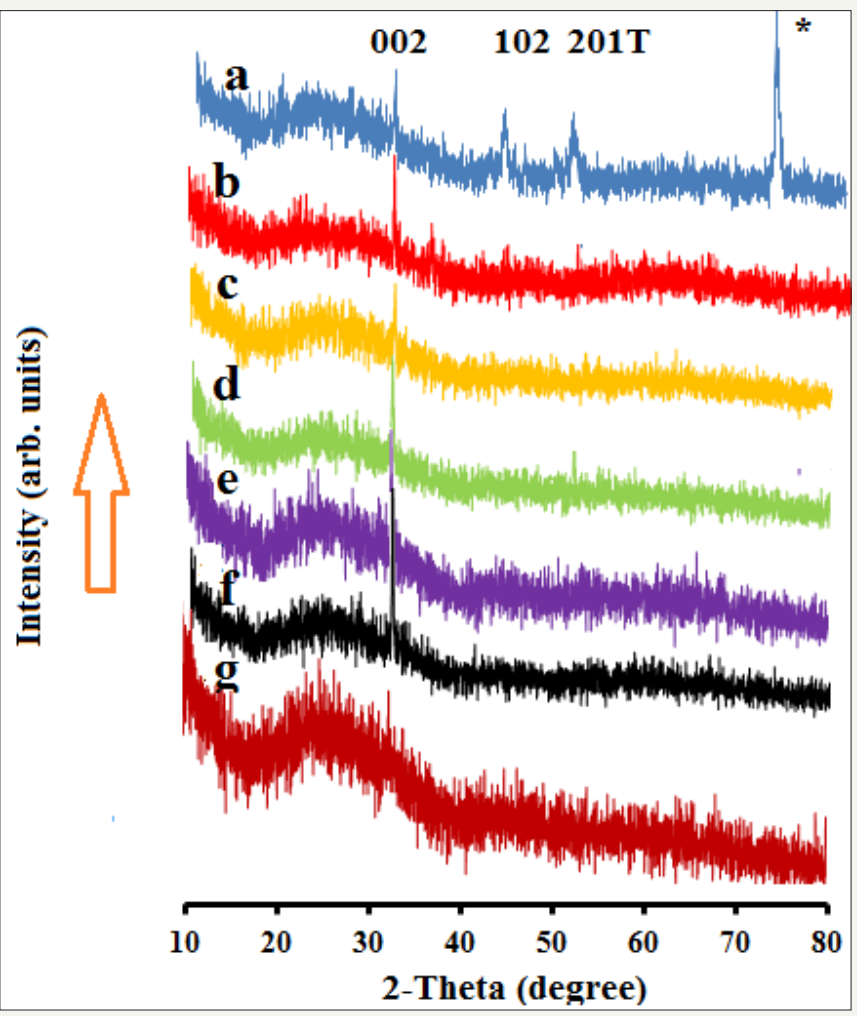

Figure 2: PXRD patterns of FeSe thin films fabricated by AACVD of 1-(4-methoxybenzoyl)-3-(4-ferrocenylphenyl) selenourea $(\mathrm{P} 4 \mathrm{Me})$, a) without using any surfactant, b) with $1 \mathrm{span}$ : $1 \mathrm{P} 4 \mathrm{Me}, \mathrm{c}$ ) with 2 span: $1 \mathrm{P} 4 \mathrm{Me}$, d) with 3 span: $1 \mathrm{P} 4 \mathrm{Me}$, e) with 1 triton: $1 \mathrm{P} 4 \mathrm{Me}, \mathrm{f})$ with 2triton: $1 \mathrm{P} 4 \mathrm{Me}, \mathrm{g})$ with 3triton: $1 \mathrm{P} 4 \mathrm{Me}$.

Figure 3 presents the SEM images of FeSe thin films by using $\mathrm{P} 4 \mathrm{Me}$ as a precursor in the presence (films b-g) and absence of surfactants (film a). Film a, which was fabricated with P4Me without using any surfactant shows somewhat irregular morphology with dominance of spherical particles. By using span
1:1 with P4Me during AACVD gives film $b$ which in comparison with film a has smaller sized particles with more uniform spherical shape. By increasing the molar ratio of span with P4Me to 2:1, size of FeSe particles decreases further but with aggregation to cubic type morphology (film c). Film $\mathrm{d}$ is the result of 3 times higher 
concentration of span with $\mathrm{P} 4 \mathrm{Me}$ and shows complete change of morphology to broken noodles shape. Film e was fabricated by using triton at a molar ratio of 1:1 with $\mathrm{P} 4 \mathrm{Me}$ and has well defined spherical particles as compared to film a in which no surfactant was used. Increasing the concentration of triton with P4Me to
2:1 increases the FeSe spheres (film e) and at a molar ratio of 3:1 particle size is enormously reduced (film $\mathrm{f}$ ). EDS analysis shows the presence of Fe and Se at a ratio of almost 1:1, although there are peaks available from the glass support as well (Figure 3).
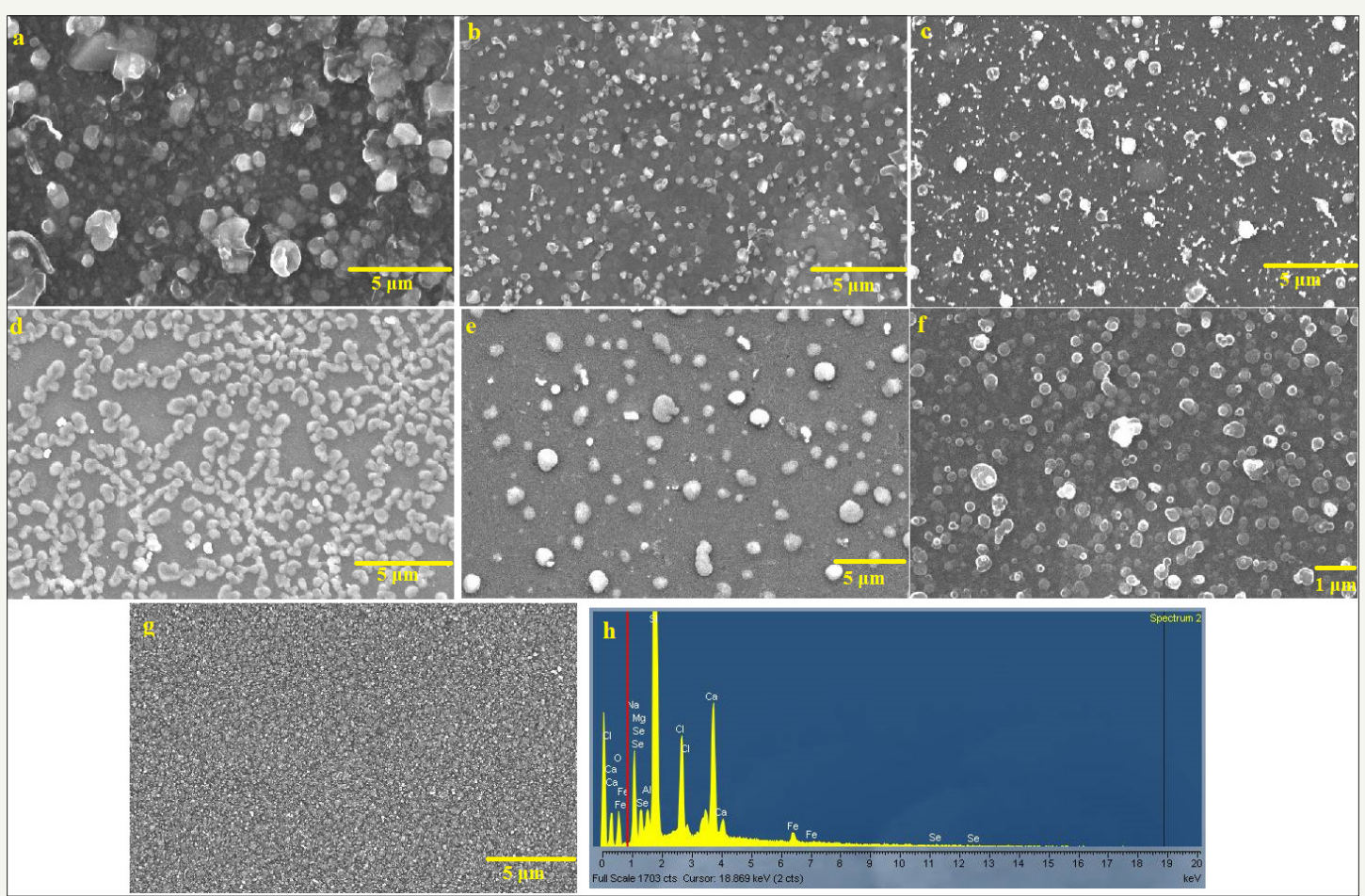

Figure 3: SEM images of FeSe thin films fabricated by AACVD of 1-(4-methoxybenzoyl)-3-(4-ferrocenylphenyl) selenourea (P4Me), a) without using any surfactant, b) with 1 span: $1 \mathrm{P} 4 \mathrm{Me}$, c) with 2 span: $1 \mathrm{P} 4 \mathrm{Me}$, d) with 3 span: $1 \mathrm{P} 4 \mathrm{Me}, \mathrm{e})$ with 1 triton: $1 \mathrm{P} 4 \mathrm{Me}, \mathrm{f}$ with 2triton: 1P4Me, g) with 3triton: 1P4Me, h) EDS image of film a.

\section{Proposed mechanism of surfactant action}

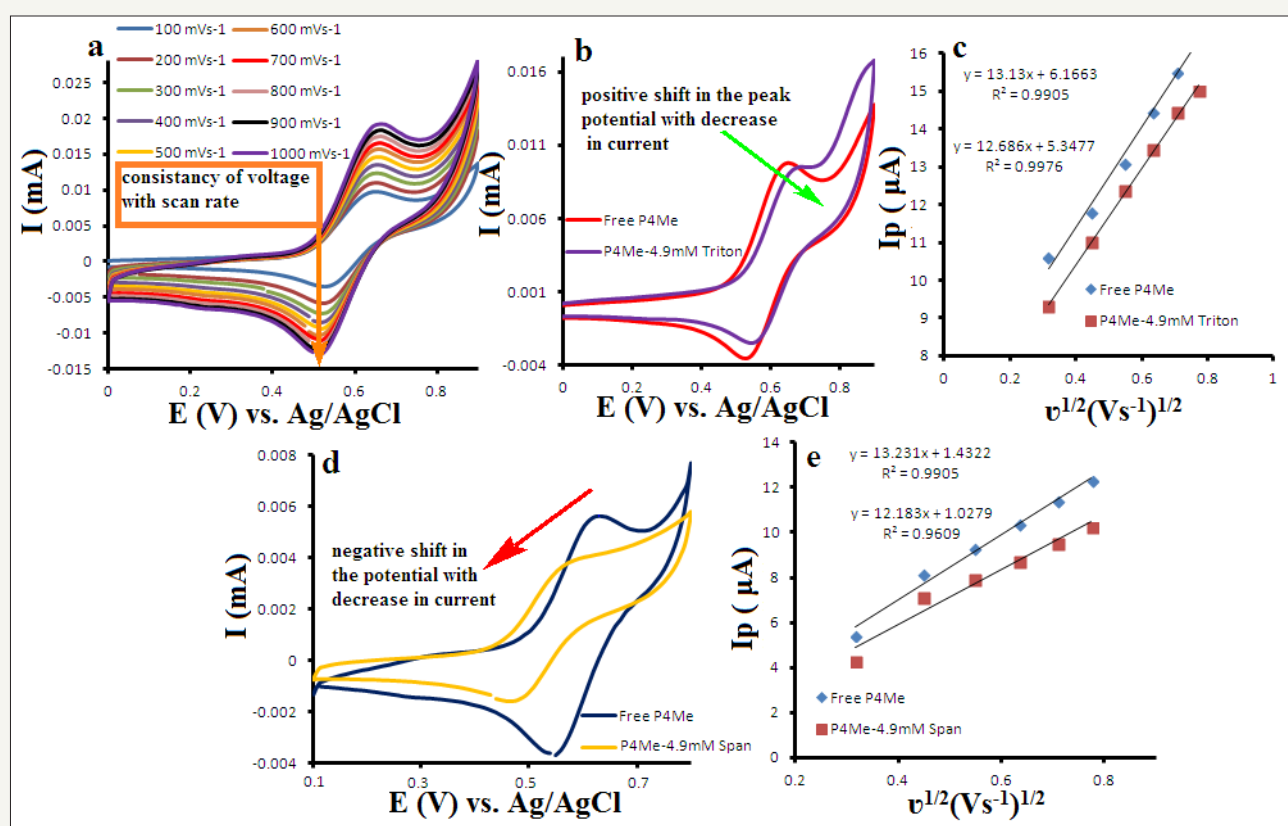

Figure 4: a) CV of P4Me at different scan rates, b) $\mathrm{CV}$ of P4Me with and without triton, c) Plot of I vs. scan rate for the determination of diffusion coefficient for free and triton bound P4Me, d) CV of P4Me with and without span, e) Plot of I vs. scan rate for the determination of diffusion coefficient for free and span bound P4Me. 
An attempt was made to determine the mechanism for the interaction of surfactants with $\mathrm{P} 4 \mathrm{Me}$ using cyclic voltammetry (CV). In CV P4Me provides a couple of well-defined redox peaks in a $100 \%$ reversible electrochemical process which is evident by the consistency of the voltage at different scan rates, difference of $\sim 59 \mathrm{mV}$ between oxidation and reduction peaks for one electron system and almost equal current intensities of oxidation and reduction peaks [22,29] (Figure 4a). To evaluate the interaction between triton and $\mathrm{P} 4 \mathrm{Me}$, cyclic voltammograms of $1 \mathrm{mM}$ free $\mathrm{P} 4 \mathrm{Me}$ and P4Me-triton adduct were compared with each other (Figure $4 \mathrm{~b}$ ). There is a clear positive shift in the peak potential of $\mathrm{P} 4 \mathrm{Me}$-triton adduct relative to free $\mathrm{P} 4 \mathrm{Me}$ with a decrease in the current values (Figure $4 \mathrm{~b}$ ). The formation of adduct was confirmed by lower diffusion coefficient of P4Me-triton adduct $\left(4.41 \times 10^{-7} \mathrm{~cm}^{2} \mathrm{~s}^{-1}\right)$ relative to free $\mathrm{P} 4 \mathrm{Me}\left(4.72 \times 10^{-7} \mathrm{~cm}^{2} \mathrm{~s}^{-1}\right)$ (Figure 4c). Whereas in case of span, $\mathrm{P} 4 \mathrm{Me}$-span adduct shows a negative shift in the peak potential relative to free $\mathrm{P} 4 \mathrm{Me}$ with a prominent decrease in the peak current. This negative shift in the peak potential is attributed to the electrostatic interactions of $\mathrm{P} 4 \mathrm{Me}$ with span. Formation of adduct was confirmed by lower diffusion coefficient of P4Me-span $\left(4.07 \times 10^{-7} \mathrm{~cm}^{2} \mathrm{~s}^{-1}\right)$ adduct relative to free $\mathrm{P} 4 \mathrm{Me}\left(4.72 \times 10^{-7} \mathrm{~cm}^{2} \mathrm{~s}^{-1}\right)$ however the decrease in the current values and shifts in the potential are visibly greater for span than triton. This can be explained by looking at the structure of span and triton which show the presence of electronegative groups in the head of span which make it suitable for the electrostatic interaction with positively charged ferrocenium of P4Me but in case of triton this electronegative head is absent that's why chances of electrostatic interactions are also minimized (Figure 5). So, we propose that the surfactants during humidification and thermal decomposition form adducts with the precursor to force the changes in the morphology and different effect for two different surfactants was because of the different extent of interactions, depending upon the structures of the surfactants.

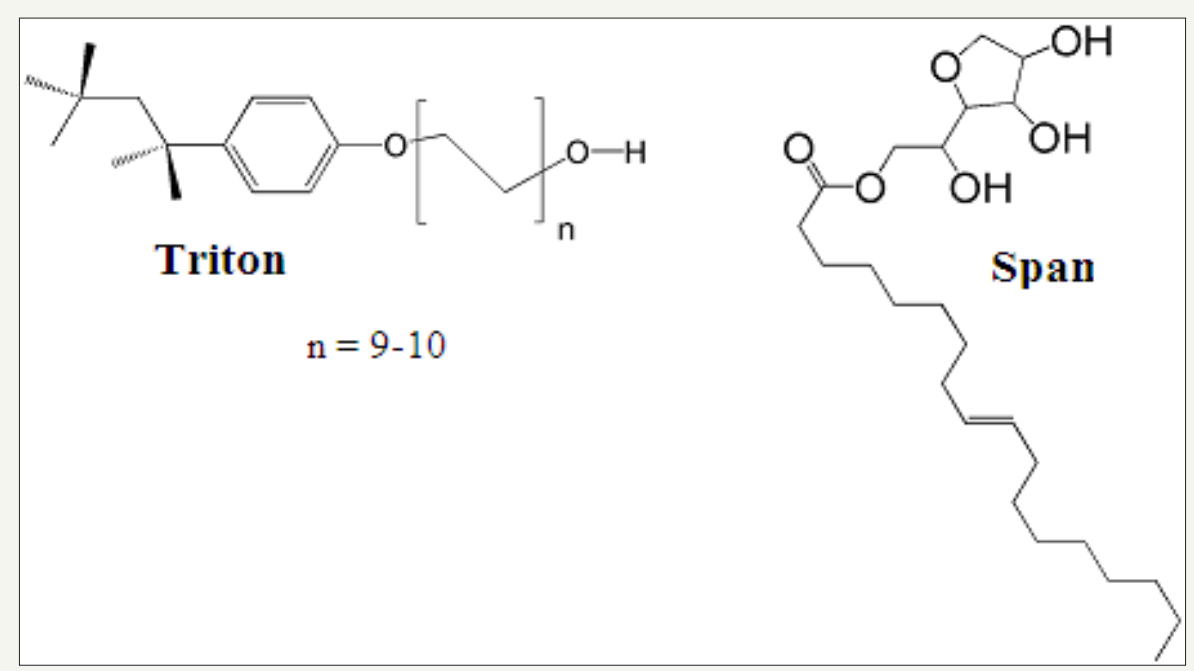

Figure 5: Structure of span and triton.

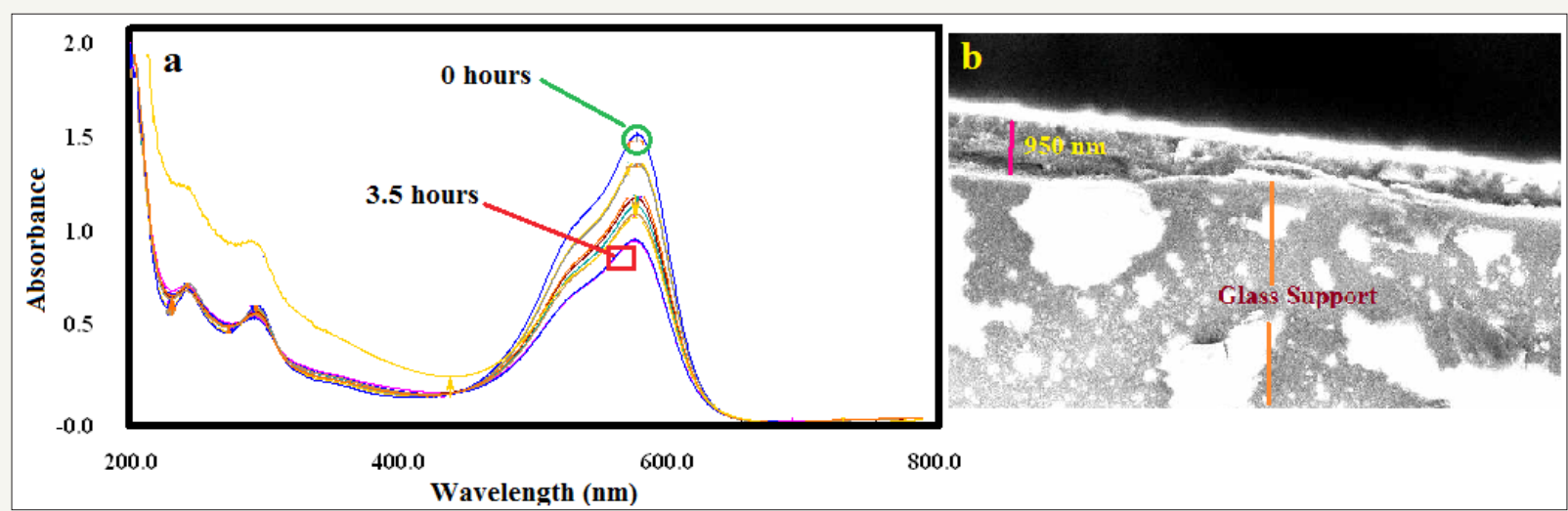

Figure 6: a) Degradation of methyl violet in the presence of direct sunlight using UV-vis spectroscopy, b) SEM image of film a (fabricated using P4Me without surfactants) after cutting it with diamond knife cutter.

\section{Photocatalytic activity}

Film fabricated without using any surfactant (film a) was also used for the degradation of methyl violet (MV) in the presence of direct sunlight using UV-vis spectroscopy. Figure 6a shows that
$40 \%$ of methyl violet is degraded in $3.5 \mathrm{hrs}$. This value appears to be inferior to the different values reported in literature [30] for boron doped diamond and platinum anodes, [31] silver loaded titanium oxide [32], activated carbon [33], flower like titanium 
oxide microspheres [34] and cobalt doped mesoporous titaniasilica catalyst [35] but 40\% degradation which we are reporting in this manuscript is only for the 950nm thick FeSe film (Figure 6b).

\section{Conclusion}

Ferrocene incorporated selenourea named 1-(4-methoxybenzoyl)-3-(4-ferrocenylphenyl) selenourea (P4Me) has been successfully converted to NiAs type hexagonal FeSe thin films with aerosol assisted chemical vapor deposition at $450{ }^{\circ} \mathbf{C}$. We observed that morphologies of the fabricated FeSe thin films are dependent on the type and concentrations of the surfactants used during AACVD by keeping all the other conditions of film fabrication constant. In a quest to know about the mechanism of surfactant action, we propose with the help of cyclic voltammetry results that there is an adduct formation between our single source precursor (P4Me) and surfactants. These adducts govern the morphological changes. We have also reported the degradation of methyl violet by FeSe.

\section{Acknowledgement}

We are thankful to the Higher Education Commission, Islamabad, Pakistan for financial support.

\section{References}

1. Blackman CS, Carmalt CJ, Parkin IP, Apostolico L, Molloy KC, et al. (2002) Single-source CVD routes to titanium phosphide. Dalton Trans, pp. 2702-2709.

2. Thomas T, Blackman CS, Parkin IP, Carmalt CJ (2010) Atmospheric pressure chemical vapour deposition of $\mathrm{TiCl}_{4}$ and $\mathrm{tBuAsH}_{2}$ to form titanium arsenide thin films. Eur J Inorg Chem 2010(36): 5629-5634.

3. Choy KL (2003) Chemical vapour deposition of coatings. Prog Mater Sci 48(2): 57-170.

4. Marchand P, Hassan IA, Parkin IP, Carmalt CJ (2013) Aerosol-assisted delivery of precursors for chemical vapour deposition: expanding the scope of CVD for materials fabrication. Dalton Trans.

5. Li L, Yang Z, Sun Y, Zhanssg J, Shen D, Zhang Y (2011) Superconductivity and magnetism in FeSe thin films grown by metal-organic chemical vapor deposition. Supercond Sci Technol 24: 015010.

6. Dutta AK, Maji SK, Srivastava DN, Mondal A, Biswas P, et al. (2012) Synthesis of FeS and FeSe nanoparticles from a single source precursor: a study of their photocatalytic activity, peroxidase-like behavior, and electrochemical sensing of H2O2. ACS Appl Mater Interfaces 4(4): 19191927.

7. Demura S, Okazaki H, Ozaki T, Hara H, Kawasaki Y, et al. (2013) Electrodeposition as a new route to synthesize superconducting FeSe. Solid State Commun 154: 40-42.

8. Chen TK, Luo JY, Ke CT, Chang HH, Huang TW, et al. (2010) Lowtemperature fabrication of superconducting FeSe thin films by pulsed laser deposition. Thin Solid Films 519(5): 1540-1545

9. Hara Y, Takase K, Yamasaki A, Sato H, Miyakawa N, et al. (2010) Structura and physical properties of FeSe crystals fabricated by the chemical vapor transport method. Physica C: Superconductivity. 470(1): 313-314.

10. Ubale A, Sakhare Y, Bombatkar S (2013) Influence of the complexing agent ( $\mathrm{Na}_{2}$-EDTA) on the structural, morphological, electrical and optical properties of chemically deposited FeSe thin films. Mater Res Bull 48(9): 3564-3571.

11. Wu XJ, Zhang ZZ, Zhang JY, Ju ZG, Li BH, et al. (2008) Growth of FeSe on general substrates by metal-organic chemical vapor deposition and the application in magnet tunnel junction devices. Thin Solid Films 516(18): 6116-6119.
12. Ubale A, Sakhare Y (2013) Effect of substrate temperature on optical, structural and electrical properties of FeSe thin films deposited by Spray pyrolysis technique. J Phys Chem Solids 74(10): 1459-1464.

13. Agatsuma S, Yamagishi T, Takeda S, Naito M (2010) MBE growth of FeSe and $\mathrm{Sr}_{1-\mathrm{x}} \mathrm{K}_{x} \mathrm{Fe}_{2} \mathrm{As}_{2}$. Physica C: Superconductivity 470(20): 1468-1472.

14. Li Z, Ju J, Tang J, Sato K, Watahiki M, Tanigaki K (2010) Structural and superconductivity study on $\alpha$-FeSex. J Phys Chem Solids 71(4): 495-498.

15. Umeyama N, Tomura M, Takase K, Hara S, Horiguchi S, et al. (2010) Superconductivity on FeSe synthesized by various sintering temperatures. Physica C: Superconductivity 470(1): S518-S520.

16. Qi X, Wang JY, Kuo JC, Yates KA, Cohen LF (2011) Superconducting property and $\mathrm{Fe}$ valence state of FeSe thick films grown from high temperature solution. J Alloys Comp 509(22): 6350-6353.

17. Chang CC, Wang CH, Wen MH, Wu YR, Hsieh YT, et al. (2012) Superconductivity in PbO-type tetragonal FeSe nanoparticles. Solid State Commun 152(8): 649-652.

18. Guo X, Yi P, Yang Y, Cui J, Xiao S, Wang W (2013) Effects of surfactants on agarose-based magnetic polymer electrolyte for dye-sensitized solar cells. Electrochim Acta 90: 524-529.

19. McNally CS, Turner DP, Kulak AN, Meldrum FC, Hyett G (2012) The use of cationic surfactants to control the structure of zinc oxide films prepared by chemical vapour deposition. Chem Commun 48(10): 1490-1492.

20. Hussain RA, Badshah A, Haider N, Khan MD, Lal B (2014) Effect of surfactants on the morphology of FeSe films fabricated from a single source precursor by aerosol assisted chemical vapor deposition. J Chem Sci 127(3): 499-507.

21. Hussain RA, Badshah A, Yasmin F, Khan MD, Tahir MN (2014) Aerosol assisted chemical vapor deposition for iron selenide thin films from single source ferrocene incorporated selenourea precursor in the presence of surfactants. Aust J Chem 68(2): 298-306.

22. Hussain RA, Badshah A, Younis A, Khan MD, Akhtar J (2014) Iron selenide films by aerosol assisted chemical vapor deposition from single source organometallic precursor in the presence of surfactants. Thin Solid Films 567: 58-63.

23. Hussain RA, Badshash A, Sohail M, Lal B, Altaf AA (2013) Synthesis, chemical characterization, DNA interaction and antioxidant studies of ortho, meta and para fluoro substituted ferrocene incorporated selenoureas. Inorg Chim Acta 402: 133-139.

24. Hussain RA, Badshah A, Tahir MN, Lal B, Khan IA (2013) Synthesis, chemical characterisation, and DNA binding studies of ferroceneincorporated selenoureas. Aust J Chem 66(6): 626-634.

25. Hussain RA, Badshah A, Akbar K (2014) Comparative DNA binding and antioxidant studies of acetyl and benzoyl substituted ferrocene incorporated selenoureas, Russ J Electrochem 51(3): 198-208.

26. Hussain RA, Badshah A, Marwat S, Yasmin F, Tahir MN (2014) Iron selenide nanoparticles coated on carbon nanotubes from single source ferrocene incorporated selenourea precursor for fuel cell and photocatalytic applications. J Organomet Chem 769: 58-63.

27. Hussain RA, Badshah A, Shah A (2014) Synthesis and biological applications of selenoureas. Appl Organomet Chem 28(2): 61-73.

28. Hussain RA, Badshah A, Sohail M, Lal B, Akbar K (2013) Synthesis, chemical characterization, DNA binding and antioxidant studies of ferrocene incorporated selenoure. J Mol Struct 1048: 367-374.

29. Hussain RA, Badshah A, Tahir MN, Hassan TU, Bano A (2014) Synthesis, chemical characterization, DNA binding, antioxidant, antibacterial, and antifungal activities of ferrocence incorporated selenoureas. J Biochem Mol Toxicol 28(2): 60-68.

30. Yu L, Huang Y, Yang Y, Xu Y, Wang G, Yang S (2013) Photocatalytic degradation of organic dyes by $\mathrm{H}_{4} \mathrm{SiW}_{6} \mathrm{Mo}_{6} \mathrm{O}_{40} / \mathrm{SiO}_{2}$ Sensitized by $\mathrm{H}_{2} \mathrm{O}_{2}$. Int J Photoenergy. 
31. Hamza M, Abdelhedi R, Brillas E, Sirés I (2009) Comparative electrochemical degradation of the triphenylmethane dye Methyl Violet with boron-doped diamond and Pt anodes. J Electroanal Chem 627(1-2): 4150 .

32. Sökmen M, Allen DW, Akkaș F, Kartal N, Acar F (2001) Photo-degradation of some dyes using Ag-loaded titaniumdioxide. Water, Air, and Soil Pollution 132(1-2): 153-163.

33. Chen S, Zhang J, Zhang C, Yue Q Li Y, et al. (2010) Equilibrium and kinetic studies of methyl orange and methyl violet adsorption on activated carbon derived from Phragmites australis. Desalination 252(1-3): 149156.

34.Xiang Q Yu J, Jaroniec M (2011) Tunable photocatalytic selectivity of $\mathrm{TiO}_{2}$ films consisted of flower-like microspheres with exposed $\{001\}$ facets. Chem Commun 47: 4532-4534.

35. Li J, Liu S, He Y, Wang J (2008) Adsorption and degradation of the cationic dyes over Co doped amorphous mesoporous titania-silica catalyst under UV and visible light irradiation. Microporous Mesoporous Mater 115(3): 416-425.

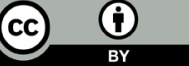

Creative Commons Attribution 4.0 International License

For possible submissions Click Here

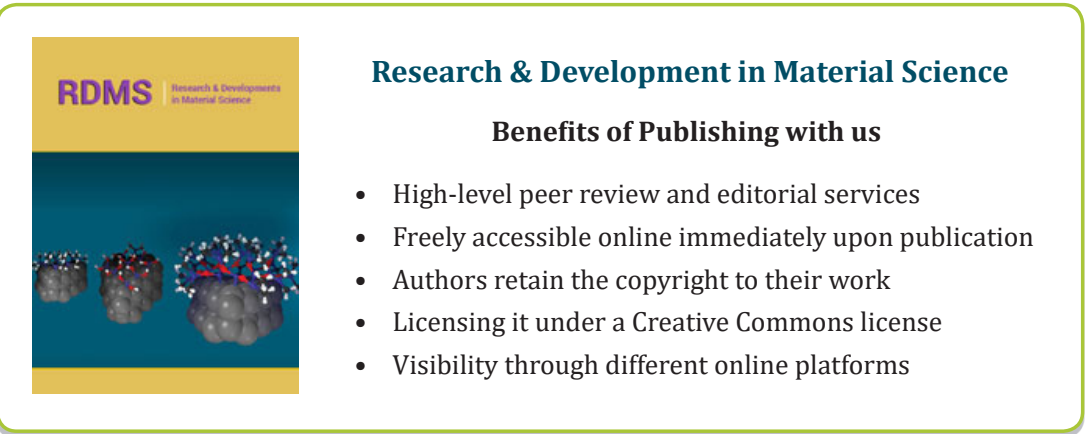

